\title{
Landscapes in the Eastern Mediterranean between the Future and the Past
}

\author{
Ioannis N. Vogiatzakis ${ }^{1, *(\mathbb{C})}$, Theano S. Terkenli ${ }^{2}$, Maria Gabriella Trovato ${ }^{3}$ and \\ Nizar Abu-Jaber 4 \\ 1 School of Pure \& Applied Sciences, Open University of Cyprus, PO Box 12794, 2252 Nicosia, Cyprus \\ 2 Department of Geography, University of the Aegean, 81100 Mytilini Lesvos, Greece; t.terkenli@aegean.gr \\ 3 Landscape Design and Ecosystem Management, Faculty of Agricultural and Food Sciences, American \\ University of Beirut, Riad El-Solh, Beirut 1107-2020, Lebanon; mt63@aub.edu.lb \\ 4 Center for the Study of Natural and Cultural Heritage, German Jordanian University, P.O. Box 35247, \\ Amman 11180, Jordan; nizar.abujaber@gju.edu.jo \\ * Correspondence: ioannis.vogiatzakis@ouc.ac.cy, Fax: +357 22411601
}

Received: 7 December 2018; Accepted: 13 December 2018; Published: 18 December 2018

Landscapes have long been viewed as complex, synthetic entities reflecting the human imprint upon the land. Efforts have been made for a number of decades now to plan, manage, and use them on a "multi-functional" and sustainable basis, integrating all of their dimensions-ecological, economic, socio-cultural, historical, aesthetic, etc. (Wascher 2000 [1]; Wu 2013 [2]). Landscape scale approaches have been fundamental to the understanding of past and present cultural evolution and are now considered to be an appropriate spatial framework for the analysis of land systems sustainability (Buttimer 1998 [3]; Terkenli 2005 [4]). The methods and tools of landscape analysis and intervention have also greatly evolved since their early development in Europe and North America (Fairclough et al. 2018 [5]). Although significant progress has been made, there remain many issues which are understudied or not investigated at all, at least in a Mediterranean context, as local contexts greatly impact the applicability of landscape characterization and planning approaches.

This special volume in LAND focuses on the application of landscape theory and practice in the Eastern Mediterranean and mainly reports on the outcomes of an international conference held in Jordan in December 2015 upon the closure of the MEDSCAPES PROJECT (Vogiatzakis et al. 2015 [6]), with the title "International Conference on Landscapes of the Eastern Mediterranean: challenges, opportunities, prospects and accomplishments". The focus of this volume constitutes a timely and growing area of research interest, not only because these landscapes have so far been understudied, but also because the Eastern Mediterranean region is a rich site of strikingly variegated, long-standing, multi-cultural human-environmental interactions (Braudel 1972 [7]; King et al. 1997 [8]; Grove and Rackham 2001 [9]; Lowenthal 2015 [10]). These interactions, resting on and taking shape through millennia of continuity in tradition, have been striving to adapt to technological advances, while currently juggling numerous multi-layered socio-economic and climate-environmental crises.

Landscape science and public awareness in Europe have been progressing in leaps and bounds. The challenges involved in landscape-related issues and fields are, nonetheless, still multiple, and refer to landscape stewardship and protection as well as to the development of comprehensive relevant theoretical and methodological approaches, in tandem with public sensitization and participatory governance, and in coordination with appropriate top-down planning and policy instruments. By definition (Council of Europe, 2000 [11]), landscape has long been established as the medium and product of human ways of relating to our surroundings. Significant inroads have been made in recent research endeavors towards almost all aspects of landscape analysis and interventions, including landscape ecology, rural sociology, and urban gentrification. For instance, the theory of landscape ecology, founded and described in the seminal work by Forman and Godron (1986) [12], set the scene 
for a paradigm shift in ecology from site-based to landscape-based processes. Although the landscape may appear to be a principally material or physical entity, it is experienced as a synthetic whole through living, traveling, or simply seeing it from afar, as illustrated by recent scientific perspectives, such as "interactive", "enactive", "embodied", or "more-than-representational" geographies. The erroneous distinction between natural and cultural landscapes is still encountered: an artificial distinction, since, in the Mediterranean — and particularly the Eastern Mediterranean-very few areas free of human intervention remain (Vogiatzakis 2012 [13]; Vogiatzakis et al. 2008 [14]). Indeed, Mediterranean landscapes merit increased and more focused attention, on the basis of their historically continuous and heavy exposure to human impact (Lowenthal 2015 [10]), exacerbated, in recent decades, by conditions of strife and crisis.

The significance, then, of this task of applying conventional Western knowledge and practices to this part of the world first lies in filling a gap. The Eastern Mediterranean has been relatively lagging and in great need of such methods and spatial interventions vis-à-vis its landscapes, but finding itself increasingly at a crossroads where serious such efforts are starting to be undertaken. Meanwhile, it represents an especially fragile part of the earth, where cultural and environmental resource deterioration has been progressing at rapid rates (i.e. desertification, water depletion, cultural destruction, ecological impoverishment etc.). On the basis of the fragility of the Eastern Mediterranean region, due to its location, fragmented and confined configuration, intricate geomorphology and tectonism, but also due to its vulnerability (i.e. to human use, through tourism, poor or lacking planning practices, overpopulation and heavy urbanization), this collective effort becomes quite timely. It is timely not only because of rampant environmental change, presenting a series of risks and hazards, especially when combined with detrimental human impact on the land; it becomes timely and useful also because of growing forces of change and recent socio-political upheaval in this part of the world (wars, socio-economic crises, geopolitical tensions). These trends call for new inroads in landscape risk assessment methodologies, in the context of landscape decision-making and support systems. Furthermore, new information and communication technologies, referring to and assisting almost all sectors of human activity, present ever-expanding arenas of human-landscape interactions. All of these methods, tools, and technologies are showing signs of being enthusiastically embraced by the societies of the region here under focus.

While the transfer of Western knowledge and practices to the Middle East has been more or less established, the MEDSCAPES project offered some interesting reverse possibilities and potential. In this regard, a promising example concerns public participation in landscape stewardship, through lessons acquired from the Arab-speaking world, namely the HIMA traditions. Participatory practices in landscape planning and management that we have begun to apply in the 'Western' world during the past few decades have been commonplace custom in the 'Near-Eastern' world for millennia.

Finally, this undertaking highlights an area begging for further scientific exploration in terms of the long-standing historically-rooted connections and interactions between the peoples of the Eastern Mediterranean region, and continuously bearing fruit in terms of revealing its closely-knit common cultural character and trajectories. Just a few examples: Greece was enriched by Egypt and Phoenicia, Rome by Greece, Byzantium by the Balkans, Southeastern Europe by the Middle East, and so on. Most significantly, though, this collective task becomes very relevant because it attempts to elucidate and understand the very different ways in which indigenous populations of the Eastern Mediterranean have related to their surroundings through time and space, as well as their contemporary rich and variegated traditions and concepts of landscape and space.

This is broadly reflected also in the structure of this volume. The volume begins with the laying out of the cultural-historical context and significance of the project, proceeds to an analysis of Landscape Character Assessment (LCA) methodological applications and their outcomes, and closes with planning practices and tools as well as empirical lessons drawn from their implementation. In so doing, it places the discussion of specific landscapes in their socio-political and environmental contexts, applies geospatial analysis for landscape management but also reveals the role of people (stakeholders) 
and societies in LCA and landscape planning. More specifically, Moraitis [15] sets the scene for tracing the roots to common traditions in the Arabic and Byzantine cultures; these cultures seem to have played a crucial role in the subsequent shaping of Eastern Mediterranean landscapes. In Cyprus, sacred landscapes of the Archaic and Hellenistic periods are accordingly discussed by Papantoniou and Vrionis [16] as constructs of religion, politics, identity, and memory, whose change through time has been a result of socio-political and economic transformation and adaptation to changing contexts and circumstances.

Transferring methodologies and concepts from one geographical context to another is not without challenges. LCA is such an example (Fairclough et al. 2018 [5]). LCA has a significant contribution to make as a spatial framework for the rekindled concept of "multi-functional landscapes", referring to landscape provision of a range of functions, services, and human-derived benefits. Although the application of LCA in the Mediterranean region is on the increase (Vogiatzakis 2011 [17]), the paper by Griffiths [18] is perhaps the first of its kind to review the implementation and spread of LCA in the Eastern Mediterranean, effectively starting in Cyprus, before it was embraced by MEDSCAPES for a number of other case studies. Notwithstanding what may often be perceived as a uniform area (culturally, historically, physiographically), there are distinct differences between and within countries of the Eastern Mediterranean, as demonstrated in today's landscapes. Therefore, it becomes difficult to make meaningful comparisons between areal units of analysis without reference to a common spatial framework. In their paper, Vogiatzakis and Manolaki [19] use such a framework to investigate the diversity and variability of mapped landscapes, in six case studies across four Eastern Mediterranean countries.

Socio-political processes, followed by ecological system responses in time, imprint their impacts on present-day landscapes. Not only agricultural intensification and land use abandonment, but also mass tourism and migration, constantly shape new landscapes in the Mediterranean. These changes have had an impact on resources and biodiversity—some demonstrated imminently, while others, like biodiversity loss, with a time lag effect (Lindborg and Eriksson 2004 [20]). Geospatial analysis has brought new perspectives to landscape studies, by allowing variable reconstructions of the past, and novel ways of representing the present and predicting the future (Vogiatzakis and Melis 2015 [6]). As exemplified herein by a case study from southern Italy (Statuto et al [21], this volume), the developed methodology can be used to provide insights into present landscape monitoring and management, by weaving changes of the past into decision-making processes.

Landscape meanings and messages are often within the eye of the beholder, a challenge that has accompanied all landscape-related disciplines from the start. Landscape users and stakeholders come from a variety of groups with different views and often conflicting interests, in the use of landscape as space and as resource. Stakeholders' involvement in landscape assessment is of utmost importance and also advocated by the European Landscape Convention (Council of Europe 2000 [11]). The paper by Terkenli and Kavroudakis [22] in this issue assesses high-level landscape stakeholders' perceptions and understandings of landscape-related issues, threats and problems in the Eastern Mediterranean through a purposive comparative research survey of four case studies: Cyprus, Greece, Jordan and Lebanon. The paper by Makhzoumi and Al-Sabbagh [23] further illustrates this perspective, by providing an example of stakeholders' engagement in participatory planning processes in Lebanon.

Finally, planning applications of LCA have been widely employed in Europe over the last twenty years (Marušič and Jančič 1998 [24]; Wascher and Jongman 2003 [25]; Mücher et al. 2010 [26]), but are still used to a limited degree in the Mediterranean (Loupa-Ramos and Pinto-Correia 2018 [27]). In this issue, Odeh et al. [28] apply landscape characterization to two case studies in Jordan and demonstrate ways of including the results into current land-use planning practices in the country. In addition, Trovato et al. [29] provide a landscape risk assessment method and landscape decision support system (LDSS), conducted on the regional scale of the Eastern Mediterranean basin. The study is an important attempt to assess and collate the landscape character of the region by using comparable indicators 
to evaluate the risk of loss of landscape value in the Eastern Mediterranean. Furthermore, the LDSS enables users and stakeholders to build helpful scenarios in the planning process in selected areas.

Nonetheless, this volume sets out to fulfill its goals, subject to a series of delimitations, which only serve to open the ground and create space for much further and more in-depth future scientific exploration of Eastern Mediterranean landscapes, as well as ways, methods and tools to plan, manage and study them.

Author Contributions: The editorial was conceptualized by T.S. Terkenli and I.N. Vogiatzakis, M-G Trovato and N. Abu-Jaber reviewed and edited the text.

Funding: This work was partly funded by the MEDSCAPES project (ENPI-CBCMED program).

Acknowledgments: We would like to thank the German Jordanian University for organizing and hosting the International Conference on Landscapes of the Eastern Mediterranean.

Conflicts of Interest: The authors declare no conflict of interest.

\section{References}

1. Wascher, D.M. (Ed.) Landscapes and Sustainability: Proceedings of the European Workshop on Landscape Assessment as a Policy Tool, 25-26 March 1999, Strasbourg, France; European Centre for Nature Conservation: Tilburg, The Netherlands; European Centre for Nature Conservation and The Countryside Agency: Brandon Marsh, UK, 2000.

2. $\mathrm{Wu}, \mathrm{J}$. Landscape sustainability science: Ecosystem services and human well-being in changing landscapes. Landsc. Ecol. 2013, 28, 999-1023. [CrossRef]

3. Buttimer, A. Landscape and life: Appropriate scales for sustainable development. Irish Geogr. 1998, 31, 1-33. [CrossRef]

4. Terkenli, T.S. New landscape spatialities: The changing scales of function and symbolism. Landsc. Urban Plan. 2005, 70, 165-176. [CrossRef]

5. Fairclough, G.; Herlin, I.S.; Swanwick, C. Routledge Handbook of Landscape Character Assessment; Routledge: London, UK, 2018.

6. Vogiatzakis, I.N.; Manolaki, P.; Trigkas, V. (Eds.) LCA training and Implementation. In Medscapes WP5 Final Report; Open University of Cyprus: Nicosia, Cyprus, 2016.

7. Braudel, F. The Mediterranean and the Mediterranean World in the Age of Phillip II, Vol 1; HarperCollins Publishers: New York, NY, USA, 1972.

8. King, R.; Proudfoot, L.; Smith, B. (Eds.) The Mediterranean: Environment and Society; Taylor \& Francis: London/Arnold, UK, 1997.

9. Grove, A.T.; Rackham, O. The Nature of Mediterranean Europe: An Ecological History; Yale University Press: New Haven, CT, USA, 2001.

10. Lowenthal, D. Geography, history and heritage: A Mediterranean overview. In Connections, Mobilities, Urban Prospects and Environmental Threats: The Mediterranean in Transition; Terkenli, T., Douguédroit, A., Cassar, L.F., Eds.; Cambridge Scholars Publishing: Newcastle upon Tyne, UK, 2015; pp. 1-50.

11. Council of Europe. European Landscape Convention; European Treaty Series-No. 176; Council of Europe: Florence, Italy, 2000.

12. Forman, R.; Godron, M. Landscape Ecology; John Wiley: New York, NY, USA, 1986.

13. Vogiatzakis, I.N. (Ed.) Mediterranean Mountain Environments; Wiley-Blackwell: Oxford, UK, 2012.

14. Vogiatzakis, I.N.; Pungetti, G.; Mannion, A. (Eds.) Mediterranean Island Landscapes: Natural and Cultural Approaches; Landscape Series Volume 9; Springer Publishing: New York, NY, USA, 2008.

15. Moraitis, K. The Cultural Landscape Past of the Eastern Mediterranean: The Border Lord's Gardens and the Common Landscape Tradition of the Arabic and Byzantine Culture. Land 2018, 7, 28. [CrossRef]

16. Papantoniou, G.; Vionis, A.K. Landscape Archaeology and Sacred Space in the Eastern Mediterranean: A Glimpse from Cyprus. Land 2017, 6, 40. [CrossRef]

17. Vogiatzakis, I.N. Mediterranean experience and practice in Landscape Character Assessment. Ecol. Mediterr. 2011, 37, 17-31.

18. Griffiths, G. Transferring landscape character assessment from the UK to the Eastern Mediterranean: Challenges and perspectives. Land 2018, 7, 36. [CrossRef] 
19. Vogiatzakis, I.N.; Manolaki, P. Investigating the diversity and variability of Eastern Mediterranean Landscapes. Land 2017, 6, 71. [CrossRef]

20. Lindborg, R.; Eriksson, O. Historical landscape connectivity affects present plant species diversity. Ecology 2004, 85, 1840-1845. [CrossRef]

21. Statuto, D.; Cillis, G.; Picuno, P. Using Historical Maps within a GIS to Analyze Two Centuries of Rural Landscape Changes in Southern Italy. Land 2017, 6, 65. [CrossRef]

22. Terkenli, T.S.; Kavroudakis, D. A Stakeholders' Analysis of Eastern Mediterranean Landscapes: Contextualities, Commonalities and Concerns. Land 2017, 6, 90. [CrossRef]

23. Makhzoumi, J.; Al-Sabbagh, S. Landscape and Urban Governance: Participatory Planning of the Public Realm in Saida, Lebanon. Land 2018, 7, 48. [CrossRef]

24. Marušič, J.; Jančič, M. Regional Distribution of Landscape Types in Slovenia: Methodological Bases; Ministry of Environment and Physical Planning: Ljubljana, Slovenia, 1998.

25. Washer, D.; Jongman, R. (Eds.) European Landscapes: Classification, Evaluation and Conservation; Environment Technical Reports; European Environment Agency: Copenhagen, Denmark, 2003.

26. Mücher, C.A.; Klijn, J.A.; Wascher, D.M.; Schaminée, J.H.J. A new European Landscape Classification (LANMAP): A transparent, flexible and user-oriented methodology to distinguish landscapes. Ecol. Indic. 2010, 10, 87-103. [CrossRef]

27. Loupa-Ramos, I.; Pinto-Correia, T. Landscape Character Assessment across scales: Insights from the Portuguese experience of policy and planning. In Routledge Handbook of Landscape Character Assessment; Routledge: London, UK, 2018; pp. 124-135.

28. Odeh, T.; Boulad, N.; Abed, O.; Abu Yahya, A.; Khries, N.; Abu-Jaber, N. The Influence of Geology on Landscape Typology in Jordan: Theoretical Understanding and Planning Implications. Land 2017, 6, 51. [CrossRef]

29. Trovato, M.G.; Ali, D.; Nicolas, J.; El Halabi, A.; Meouche, S. Landscape risk assessment model and decision support system for the protection of the natural and cultural heritage in the Eastern Mediterranean Area. Land 2017, 6, 76. [CrossRef]

(C) 2018 by the authors. Licensee MDPI, Basel, Switzerland. This article is an open access article distributed under the terms and conditions of the Creative Commons Attribution (CC BY) license (http://creativecommons.org/licenses/by/4.0/). 